\title{
Differentiation status of rat enterocytes after intestinal adaptation to jejunoileal bypass
}

\author{
V Albert, G P Young
}

\begin{abstract}
The differentiation status of epithelial cells in intestinal adaptation remains unclear. To determine whether enterocytes reach optimum maturity following adaptation after $85 \%$ shortening of the rat gut by jejunoileal bypass surgery, activities of two brush border enzymatic markers of differentiation, alkaline phosphatase and sucrase, were examined in subpopulations of epithelial cells isolated sequentially from the villus/crypt axis of normal (sham operated) and hyperplastic mucosa. In jejunal villi, adaptational hyperplasia was associated with an increase in total epithelial alkaline phosphatase, but not total sucrase, activity; alkaline phosphatase activity increased most obviously in cells at the $11-50 \%$ position (from the tip) on villi. In hyperplastic ileal villi, total alkaline phosphatase activity fell, although sucrase activity did not change significantly. Specific activity (per mg protein) of sucrase on jejunal villus epithelium was reduced by the adaptational changes to bypass; alkaline phosphatase specific activity remained unchanged. In the ileum, despite adaptational changes to bypass, there was no increase in the normally low specific activities of sucrase and alkaline phosphatase. Bypass surgery did not change the major site of expression of either enzyme on jejunal or ileal villi. In conclusion, enzymatic markers of functional differentiation are not all equally affected by adaptational hyperplasia. Hypertrophy of villi and increased cell proliferation seen in jejunum remaining exposed to luminal contents resulted in an increase in the alkaline phosphatase but not the sucrase content. This is not, therefore, the result of a simple immaturity of villus cells. Morphological adaption in the ileum, however, is not accompanied by adaptation of brush border enzyme markers of differentiation, confirming a functional immaturity in these cells. Strategies for increasing the expression of these markers may have clinical value.

(Gut 1992; 33: 1638-1643)
\end{abstract}

Compensatory structural and functional changes in the mammalian small intestine after resection or bypass surgery are well known. ${ }^{12}$ Villi become taller and broader, crypts elongate, proliferation rates increase, and the migration rate of enterocytes along the villus increases..$^{2-6}$ As enterocytes migrate towards the tip of the villus they normally undergo profound differentiative changes and are transformed into mature digestive and absorptive cells. ${ }^{7}$ Enterocytes on hypertrophied villi have a reduced life $\operatorname{span}^{3-5 x}$; this may not allow full differentiation which might reduce their digestive capacity.

There have, however, been controversy and conflicting published reports on the differentiation status and functional capacity of enterocytes on hypertrophied villi resulting from intestinal adaptation. A previous study from this laboratory ${ }^{6}$ and those of others, ${ }^{4}$ ' lend support to the concept that enterocytes on hypertrophied villi are immature, but other studies have not shown this. ${ }^{13 \cdot 14}$ In none of these has the enzymatic content of a pure preparation of isolated villus cells been directly measured in both adapting jejunum and ileum; either other cell types have contributed to protein and DNA, or both, or else enzyme activities have been measured in the brush borders isolated from the epithelium." Before one can draw conclusions about the state of differentiation of the villus cell, it is important to measure markers of differentiation in a pure preparation of epithelial cells from both jejunum and ileum.

In this study, we have examined activities of two enzymatic markers of differentiation - alkaline phosphatase and sucrase - in subpopulations of epithelial cells isolated sequentially from the villus/crypt axis of normal and hyperplastic jejunal and ileal mucosae. The aims were to determine whether enterocytes of both regions reached optimum maturity after adaptation subsequent to $85 \%$ jejunoileal bypass surgery and in which villus subpopulation these effects occurred.

\section{Methods}

ANIMAL MODEL

Twelve male Sprague-Dawley rats weighing approximately $250 \mathrm{~g}$ underwent either a sham operation or $85 \%$ jejunoileal bypass. The surgical procedure has been described previously. ${ }^{617}$ Briefly, the sham operation involved a simple jejunal transection and reanastomosis, while the $85 \%$ jejunoileal bypass resulted in a shortened gut with $5 \mathrm{~cm}$ of jejunum and $10 \mathrm{~cm}$ of ileum remaining in continuity, plus a long self emptying loop. The typical adaptive changes of thickened mucosa and bowel wall, along with taller villi, were observed in bowel remaining in continuity in animals that had undergone bypass; we have previously detailed this adaptive response.

Rats were killed 24 weeks after surgery by carbon dioxide asphyxiation; this time is adequate for the kinetics of the adaptional response to have stabilised. ${ }^{18}$ One hour before death rats were injected intraperitoneally with $\left[{ }^{3} \mathrm{H}\right]$ thymidine $(125 \mu \mathrm{Ci} / 250 \mathrm{~g})$. The following 10 $\mathrm{cm}$ standardised intestinal segments were taken: a duodenojejunal segment (jejunum) just proximal to the anastomosis, and an ileal segment $1 \mathrm{~cm}$ proximal to the caecum. These segments were rinsed clean with ice cold saline containing the 
protease inhibitors $1 \mathrm{mM}$ phenylmethyl-sulfonyl fluoride (Sigma Chemical Co) and 10-20 KIU/ $\mathrm{ml}$ aprotinin (Bayer Pharmaceutical Co, Botany, NSW).

\section{CELL ISOLATION}

The method of epithelial cell isolation was based on those of Weiser ${ }^{19}$ and Gratecos et al..$^{20}$ At room temperature a flanged plastic ( $1 \mathrm{~mm}$ internal diameter) catheter was positioned and tied into the end of each segment. A needle with an attached syringe was pushed into the plastic tubing; this facilitated flushing with the solutions. The segment was first distended by gently pinching one end and injecting citrate buffer (solution A of ${ }^{19}$ ) composed of $1.5 \mathrm{mM}$ $\mathrm{KCl} / 96 \mathrm{mM} \mathrm{NaCl} / 27 \mathrm{mM}$ sodium citrate/ $8 \mathrm{mM}$ $\mathrm{KH}_{2} \mathrm{PO}_{4} / 5.6 \mathrm{mM} \mathrm{Na}_{2} \mathrm{HPO}_{4}$ at $37^{\circ} \mathrm{C}$. The segment was then placed in approximately $10 \mathrm{ml}$ of this buffer in a $50 \mathrm{ml}$ Erlenmeyer flask and incubated at $37^{\circ} \mathrm{C}$ in an orbital shaking water bath (Model OW1412 Paton Industries Pty Ltd, Stepney, South Australia) for 10 minutes at $75 \mathrm{opm}$. The buffer was then decanted into a waste beaker, the lumen flushed, and the outside rinsed with $0.9 \%$ $\mathrm{NaCl}$. The segment was then distended with buffer B (10 mM phosphate buffered saline ( $\mathrm{pH}$ $7 \cdot 3) / 1.5 \mathrm{mM}$ EDTA/0.5 mM dithiothreitol $)^{20}$ at $37^{\circ} \mathrm{C}$ and placed in $20 \mathrm{ml}$ of buffer $\mathrm{B}$ in a new flask in the shaking water bath. Cells were collected by flushing the lumen at the end of each of 12 sequential periods during which cells were exposed to the isolation buffer. The duration of the periods were $2,2,2,3,4,5,7,9,10,10,10$, and 10 minutes respectively. Segments were shaken at $100 \mathrm{opm}$ for all but the last two periods when $150 \mathrm{opm}$ was used. Cells were collected at the ends of the first four periods by flushing $10 \mathrm{ml}$ of buffer $B$ through the segment and at the ends of the remainder by pulling the buffer filled segment gently between two $3 \mathrm{~g}$ glass rods to dislodge cells in a controlled manner.

The cell suspensions were collected into plastic centrifuge tubes to which $\mathrm{CaCl}_{2}$ was added to make a final concentration of $5 \mathrm{mM}$. This overcame the chelating effect of EDTA and was found in preliminary experiments to prevent disintegration of the brush border and loss of enzymes from the cell surface. Suspensions were centrifuged at $500 \mathrm{rpm}$ for 5 minutes and the cell pellet gently resuspended in $50 \mathrm{mM}$ D-mannitol $2 \mathrm{mM}$ Tris (mannitol-Tris) buffer $\mathrm{pH} \mathrm{7 \cdot 4}$. Cells were washed twice in the same manner to remove all EDTA; the final cell pellet was suspended in $1 \mathrm{ml}$ mannitol-Tris buffer. These suspensions were homogenised using a RW 20 IKA-werk (Janke and Krunkel, Staufen, Germany) stirring homogeniser and the homogenates were stored at $-20^{\circ} \mathrm{C}$ until assayed.

\section{MEASURES}

Activities of alkaline phosphatase and sucrase in the homogenates were measured spectrophotometrically, as previously described..$^{2122}$ Reaction conditions were chosen such that less than $5 \%$ of substrate was utilised and reactions were stopped during a linear phase of colour development. Protein content was measured with a Bio-Rad kit using bovine gamma globulin as standard (Bio-Rad Laboratories Pty Ltd, North Ryde, NSW, Australia). DNA content was measured fluorometrically by complexing DNA with 4,6'-diamino-2-phenyl-indole $2 \mathrm{HCl}$ using calf thymus DNA as standard. ${ }^{23}$

To determine the level of incorporation of thymidine into cells, $500 \mu \mathrm{l}$ of the isolate was added to $4 \mathrm{ml}$ of Beckman Ready Value Scintillant (Beckman Instruments Inc, Fullerton, CA, USA) and counted in a Beckman LS 3801 $\beta$-counter for 5 minutes.

\section{ANALYSIS OF DATA}

For each intestinal segment, radioactivity of cells collected during each of the 12 isolation periods was graphed (see Figure 1 for a typical rat duodenojejunal segment after jejunileal bypass) and the point in the sequential isolation at which there was a sudden rise in incorporation of $\left[{ }^{3} \mathrm{H}\right]$ thymidine (defined as that in which radioactivity was approximately twice that of the average of the first five isolates) was considered to be the point at which isolation of villus cells was complete. This often corresponded to the seventh to ninth isolation period.

As villus height and thus the number of isolation periods required to release cells from the villi varied between animals and experimental groups, it was not possible to compare directly enzyme specific activities in particular isolation periods between animals as these would represent different subpopulations from the villus. To allow comparisons between equivalent relative positions on the villus (for example tip with tip or base with base), all villus collections were standardised to four fractions according to DNA content. The first fraction, the villus tip, contained the first $10 \%$ of villus DNA (designated fraction $_{0-10}$ ), the second fraction contained the next $11-50 \%$ of DNA (fraction ${ }_{10-50}$ etc), the third contained $51-75 \%$ of DNA, and the basal villus fraction contained $76-100 \%$ of DNA. DNA content of cells collected during the individual isolation periods rarely corresponded exactly to the limits defined for each of the four fractions, and so portions of cells obtained in each isolate were allocated to villus fractions as necessary. For instance, if the cells of the first isolation period contained $7 \%$ of DNA, and of the second $6 \%$, then half of the enzyme and protein content of the second isolate would be added to the enzyme and protein content of the first isolate to allow calculation of enzyme specific activity for fraction $_{0-10}$ (the first $10 \%$ of DNA). The other half of the second isolate would be allocated to fraction $_{10-50}$. Thus cells obtained during the eight or so villus isolation periods were reallocated to four villus fractions on the basis of DNA distribution.

To determine if the amount of enzyme shifted from one site to another along the villus, an index of enzyme content was required for each villus fraction relative to that on the whole villus. This was achieved for each segment of intestine in each experimental group using the following calculation:

Enzyme activity in fraction $(\mathrm{mU} / \mathrm{ml}) \times$ average total villus protein $(\mathrm{mg} / \mathrm{ml})$ Protein content of fraction $(\mathrm{mg} / \mathrm{ml}) \quad \times$ for all rats in group 
TABLE I Effect of jejunoileal bypass ( $(I B)$ on total villus enzyme specific activity and enzyme content (values, mean (SEM))

\begin{tabular}{|c|c|c|c|c|c|c|}
\hline & \multicolumn{3}{|c|}{ Specific activity ( $m U / m g)$} & \multicolumn{3}{|c|}{ Villus enzyme content $(m U)$} \\
\hline & Sham & $\mathcal{F} I B$ & $P \star$ & Sham & $\mathcal{F} I B$ & $p^{\star}$ \\
\hline \multicolumn{7}{|c|}{ Alkaline phosphatase:; } \\
\hline Jejunum & $128(4)$ & $156(34)$ & 0.47 & $2810(290)$ & $+668(1012)$ & 0.03 \\
\hline Ileum & $17(2)$ & $14(6)$ & 0.65 & $318(28)$ & $209(96)$ & $0 \cdot 31$ \\
\hline \multicolumn{7}{|l|}{ Sucrase: } \\
\hline Jejunum & $47(10)$ & $33(4)$ & $0 \cdot 11$ & $1035(209)$ & $1000(107)$ & $0 \cdot 85$ \\
\hline Îleum & $12(3)$ & $13(4)$ & 0.80 & $227(58)$ & $196(67)$ & 0.74 \\
\hline
\end{tabular}

^Determined from planned comparisons option of the ANOVA in CSS :Statistica (see methods).

This standardised the results between rats and allowed a comparison to be made of amounts of enzyme in each villus fraction.

Total villus enzyme content (per $10 \mathrm{~cm}$ length) and specific activity were computed by adding together enzyme activity and protein contents of each isolate.

\section{STATISTICS}

Data were analysed using the quick ANOVA and planned comparison option of the statistical software package CSS:Statistica (StatSoft, Tulsa, OK, USA).

\section{Results}

\section{WHOLE VILUS EPITHELIAL ENZYME ACTIVITY}

\section{Alkaline phosphatase}

Table I shows the computed specific and tota enzyme activity for the whole villus of sham operated and bypass animals in duodenojejunum (jejunum) and ileum. Specific activity in the jejunum was significantly greater than that of the ileum in both groups $(p=0.0001)$. Jejunoileal bypass had no significant effect on total villus specific activity.

Total villus content of alkaline phosphatase also displayed a gradient along the length of the small intestine (Table I) $(\mathrm{p}=0 \cdot 0001)$. Jejunoilea bypass significantly increased alkaline phosphatase content in the jejunum while values fell (but not significantly) in the ileum (Fig 1).

\section{Sucrase activity}

The total villus sucrase activity is also shown in Table I. Maximal specific activity was seen in the jejunum with significantly lower values in ileum $(p=0.001)$. Enzyme specific activity fell in jejunum, although not significantly after

Figure 1: Gradients of specific activities of alkaline phosphatase (-) and sucrase (O) in sequential isolates from the tip of the villus to the base of the crypts in the jejunum of one jejunoileal bypass rat. Incorporation of ${ }^{3} \mathrm{H}$ thymidine is also show (A). Isolate 9, designated the first crypt isolate, demarcates the villus from the crypt zones and corresponds to the isolate at which whole crypts become more abundant at microscopy.
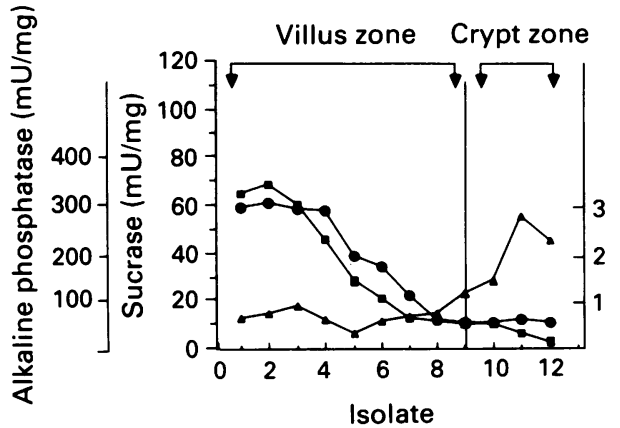

jejunoileal bypass. Total villus content of sucrase also displayed the expected gradient with decreasing activity from jejunum to ileum in both groups $(p=0 \cdot 0001)$. Bypass operation did not significantly increase enzyme activity on the villus as it did for alkaline phosphatase in jejunum.

\section{VILLUS TIP ENZYME ACTIVITY}

Table II shows that bypass surgery had no significant effect on specific activities of alkaline phosphatase or sucrase in fraction ${ }_{(1-1)}$ (the villus tip).

\section{EXPRESSION OF ENZYMES IN JEJUNAL VILI.US} FRACTIONS

\section{Alkaline phosphatase}

Figure 2A shows the gradient of specific activity relative to protein; activity at the base of the villus (fraction ${ }_{75-100}$ ) was approximately $20 \%$ of that at the tip ( fraction $_{0-10}$ ), and activity fell steeply from fraction ${ }_{0-10}$ to fraction ${ }_{10-50}$. The results of the analysis of variance (ANOVA) indicated that position of enterocytes on the villus ( $\mathrm{p}=<0.001$ ), but not jejunoileal bypass, was a highly significant determinant of specific activity.

Figure 2B shows the effect of bypass surgery on the alkaline phosphatase content in the four villus fractions. Adaptive change in response to $85 \%$ bypass significantly increased akaline phosphatase content on the villus $(p=<0.05)$ especially in fraction ${ }_{10-50}$ (Fig 2B), but did not alter the main site of enzyme activity. There was a significant interaction $(p<0.05)$ between site and operation, consistent with the major change occurring at one site.

\section{Sucrase}

There was also a gradient for sucrase activity along the villus with peak specific activity occurring in fraction ${ }_{0-10}($ Fig 2C); the gradient was not as steep as for alkaline phosphatase and activity at the base was $40 \%$ that of the tip. ANOVA indicated that the position of the enterocytes on the villus was a highly significant $(p<0.001)$ determinant of activity; the effect of adaptation to bypass produced a significant lowering $(p=0.05)$ of specific activity, this was most obvious in the upper half of the villus (Fig 2C).

Bypass surgery did not significantly change the sucrase content of the various subpopulations of

TABLE II Effect of jejunoileal bypass (FIB) on enzyme specific activity of cells at the villus tip ( fraction $\left._{1,11}\right)$ (values mean $(S E M)$

\begin{tabular}{|c|c|c|c|}
\hline & \multicolumn{3}{|c|}{ Specific activity (IU/mg) } \\
\hline & Sham & $\mathscr{I} I B$ & $p^{\star}$ \\
\hline $\begin{array}{l}\text { Alkaline phosphatase: } \\
\text { Jejunum } \\
\text { Ileum }\end{array}$ & $\begin{array}{c}340(38) \\
43(6)\end{array}$ & $\begin{array}{r}354(62) \\
51(24)\end{array}$ & $\begin{array}{l}\text { NS } \\
\text { NS }\end{array}$ \\
\hline $\begin{array}{l}\text { Sucrase: } \\
\text { Jejunum } \\
\text { Ileum }\end{array}$ & $\begin{array}{l}86(18) \\
23(3)\end{array}$ & $\begin{array}{l}61(16) \\
22(6)\end{array}$ & $\begin{array}{l}\text { NS } \\
\text { NS }\end{array}$ \\
\hline
\end{tabular}

* Determined from planned comparisons option of the ANOVA in CSS: Statistica (see methods). 

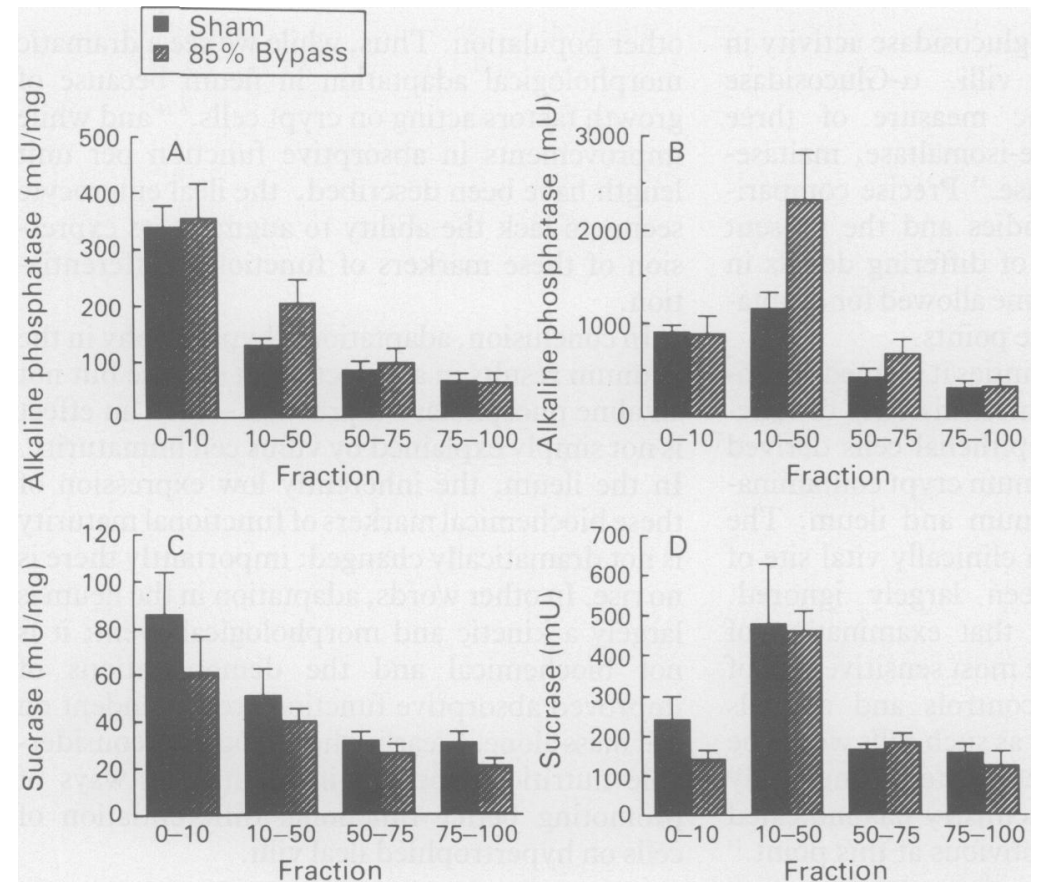

Figure 2: Specific activity and enzyme content in jejunum in each of the villus fractions for alkaline phosphatase ( $A$ and $B$ ) and sucrase $(C$ and $D)$, in sham operated (solid shading) and bypass operated (hatched shading) rats. The sequential villus cell isolates from each rat segment were divided, using DNA content, into four fractions: the villus tip containing the first $10 \%$ of villus DNA (designated fraction ${ }_{0-10}$ ); the next fraction containing the following $11-50 \%$ of DNA ( fraction $\left._{10-50}\right)$, the third fraction contained $51-75 \%$ DNA ( fraction $_{50-75}$ ) and the basal fraction with the remaining 76-100\% of DNA (fraction ${ }_{75-1000}$ ). Each vertical bar represents the mean of 4 rat segments and the error bar displays $95 \%$ confidence intervals.

villus, nor did it shift the main site of expression along the villus (Fig 2D).

\section{EXPRESSION OF ENZYMES IN ILEAL VILLUS FRACTIONS}

\section{Alkaline phosphatase}

Figure $3 \mathrm{~A}$ shows the villus gradient of alkaline phosphatase; jejunoileal bypass did not signifi-
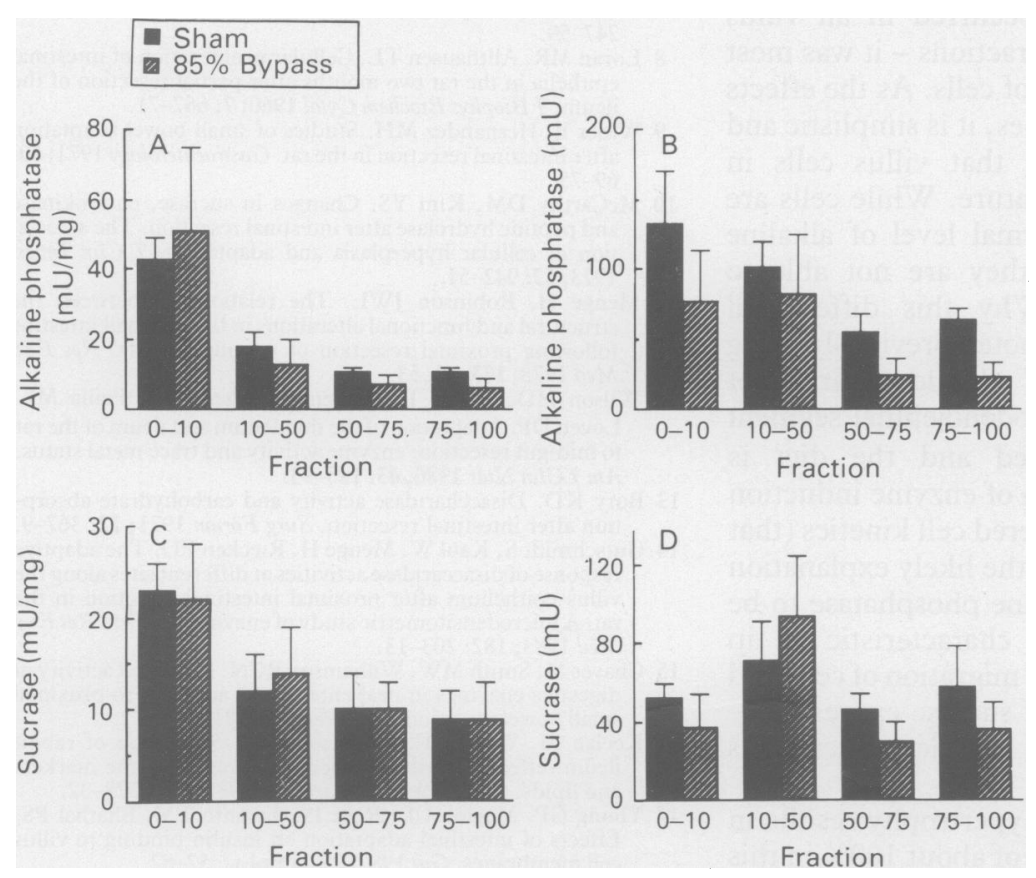

Figure 3: Specific activity and enzyme content in ileum in each of the villus fractions (see Fig 2 for details) for alkaline phosphatase $(A$ and $B)$ and sucrase $(C$ and $D)$, in sham operated (solid shading) and bypass operated (hatched shading) rats. Each vertical bar represents the mean of 4 rat segments and the error bar displays $95 \%$ confidence intervals. cantly alter expression relative to protein. ANOVA indicated that only the position of the enterocytes on the villus $(p<0.005)$ was an important determinant of enzyme specific activity. The distribution of the alkaline phosphatase content (Fig 3B) in the sham operated rats differed from that seen in the jejunum (Fig 3B); maximum activity occurred in fraction ${ }_{0-10}$ in the ileum and fraction ${ }_{10-50}$ in the jejunum. The alkaline phosphatase content in each villus subpopulation (Fig 3B) was reduced by bypass operation $(p=0.05)$.

\section{Sucrase}

The gradient for sucrase activity (Fig 3C) along the villus was not as steep as that for alkaline phosphatase and specific activity was unaffected by bypass surgery. The content of sucrase (Fig 3D) in villus fractions followed a similar distribution to that seen in the jejunum (Fig 2D). Jejunoileal bypass produced no significant changes.

\section{Discussion}

Jejunoileal bypass produces morphological and kinetic changes of adaptation in epithelium remaining exposed to luminal nutrients, identical to those which follow small intestinal resection. ${ }^{26}$ While crypt cell proliferation has been the most extensively studied of the kinetic changes, ${ }^{2+}$ changes in villus cell migration rates have also been described. Since it is clear that the biochemical and functional maturity of villus cells increase with age,${ }^{19}{ }^{20}$ the shortened villus cell life span in adaptation ${ }^{3+5815}$ points to the possibility of villus cell immaturity.

A number of studies using different approaches have attempted to address the issue of cellular maturity in adaptation. Absorptive function per unit length of hyperplastic, adapted small intestine, is increased compared with controls, ${ }^{2}$ but transport studies with isolated cells have strongly suggested that this is a result of increased cell mass despite cellular immaturity.

Brush border enzymes have often been used as biochemical markers of functional maturity as this specialised membrane and these enzymes play a pivotal role in the digestive/absorptive process. When enzymes have been assayed in mucosal homogenates, most studies have shown decreased specific activity ${ }^{6-122526}$; these changes are present after the kinetic changes have stabilised (at six weeks), ${ }^{18}$ but are also evident earlier in the adaptive process. ${ }^{12}$ Others, however, have not seen such changes in homogenates. ${ }^{13}$ Adaptational hyperplasia is not confined to the epithelium ${ }^{27}$ and confusion is created by changes in mass of other cell types included in homogenates. Some studies have shown that the different brush border enzymes are not affected equally. ${ }^{14} 1617$ Studies of isolated brush border membranes in adaptational hypertrophy have shown reduced enzymatic activity or lipid content, supporting the concept of immaturity. ${ }^{162}$ Yet two studies using quantitative histochemistry to assess the brush border enzyme response have given conflicting results. One ${ }^{14}$ observed a fall in $\alpha$-glucosidases but not $\beta$-glucosidases, while the other ${ }^{15}$ 
observed an increase in $\alpha$-glucosidase activity in cells on hypertrophied villi. $\alpha$-Glucosidase activity is a non-specific measure of three separate enzymes: sucrase-isomaltase, maltaseglucoamylase, and trehelase. ${ }^{15}$ Precise comparison between previous studies and the present study is difficult because of differing details in the experimental model, time allowed for adaptation and different reference points.

To resolve these uncertainties it seemed appropriate to examine biochemical markers of functional differentiation on epithelial cells derived from the villus, with minimum crypt contamination, and from both jejunum and ileum. The ileum is a major and often clinically vital site of adaptation, ${ }^{27}$ but has been largely ignored. Furthermore, it was felt that examination of villus tip cells might be the most sensitive way of discriminating between controls and animals with adaptive hypertrophy as such cells would be the oldest and most differentiated. One study using quantitative histochemistry has indicated that differences are more obvious at this point. ${ }^{1+}$ Two particular brush border enzymes were chosen by us for study as these have differing distributions along the villus: sucrase, which becomes well expressed soon after movement of the cell from crypt to villus, and alkaline phosphatase, which is especially expressed by cells at the tip. ${ }^{1920}$

We observed the responses in the jejunum and ileum to be different. In jejunum, where adaptational hypertrophy results in an increase in villus height of about $30-40 \%$ in this model, ${ }^{6}$ the specific activity of alkaline phosphatase in villus epithelial cells and the relatively steep gradient of activity along the villus were unchanged. However, the alkaline phosphatase content did increase with the increase in villus size. In contrast, sucrase specific activity fell almost $30 \%$, and despite the taller villi, the total amount of sucrase on villi did not rise. While the fall in sucrase specific activity occurred in all villus subpopulations - that is, fractions - it was most noticeable in the top $10 \%$ of cells. As the effects differed for the two enzymes, it is simplistic and perhaps incorrect to say that villus cells in adaptive mucosa are immature. While cells are able to progress to a normal level of alkaline phosphatase expression, they are not able to express sucrase fully. Why this differential response, which has been noted previously using mucosal homogenates, ${ }^{1+1617}$ should occur is not clear. Exposure of the duodenojejunal segment to nutrients is unchanged and the diet is unchanged; thus alteration of enzyme induction by diet is not relevant. Altered cell kinetics (that is, lifespan) do seem to be the likely explanation as one would expect alkaline phosphatase to be most affected (since it is characteristic of tip cells). Perhaps the physical migration of cells and its rate is a determinant of sucrase expression the faster the migration, the less sucrase is expressed.

In the ileum, adaptive hypertrophy results in an increase in villus height of about $100 \%$ in this model. ${ }^{6}$ Despite the jejunum like height of the villi, there were no increases in specific activities of alkaline phosphatase or sucrase in either the total villus cell mass, the tip population, or in any other population. Thus, while we see a dramatic morphological adaptation in ileum because of growth factors acting on crypt cells, ${ }^{624}$ and while improvements in absorptive function per unit length have been described, ${ }^{2}$ the ileal enterocyte seems to lack the ability to augment its expression of these markers of functional differentiation.

In conclusion, adaptational hypertrophy in the jejunum results in a reduction in sucrase but not alkaline phosphatase expression - such an effect is not simply explained by villus cell immaturity. In the ileum, the inherently low expression of these biochemical markers of functional maturity is not dramatically changed; importantly there is no rise. In other words, adaptation in the ileum is largely a kinetic and morphological event; it is not biochemical and the demonstrations of improved absorptive function are dependent on cell mass alone. Clearly, there would be considerable nutritional benefit in identifying ways of promoting better functional differentiation of cells on hypertrophied ileal villi.

The authors thank Mrs Pam Lukaszewski for typing the manuscript. This work has been supported by the National Health and Medical Research Council of Australia.

1 Booth CC, Evans KT, Menzies T. Intestinal hypertrophy following partial resection of the small bowel in the rat. $\mathrm{Br}$ Surg 1959; 46: 403-10

2 Dowling RH, Booth CC. Structural and functional changes following small intestinal resection in the rat. Clin Sci 1967 32: 139-49.

3 Loran MR, Crocker TT. Population dynamics of epithelia in the rat two months after partial resection of ileum. $\mathcal{F}$ Cell Biol 1963; 19: 285-91.

4 Hanson WR, Osborne JW. Epithelial cell kinetics in the smal intestine of the rat 60 days after resection of $70 \%$ of the ileum intestine of the rat 60 days after resection of $70 \%$ of

5 Menge H, Hopert R, Alexopoulos T, Riecken EO. Threedimensional structure and cell kinetics at different sites of rat intestinal remnants during the early adaptive response to resection. Res $\operatorname{Exp} M e d(B e r l)$ 1982; 181: 77-94

6 Albert V, Young GP, Morton CL, Robinson P, Bhathal PS Systemic factors are trophic in bypassed rat small intestine in the absence of luminal contents. Gut 1990; 31: 311-6.

7 Leblond CP, Messier B. Renewal of chief cells and goblet cells in the small intestine as shown by radioautography after injection of thymidine-H ${ }^{3}$ into mice. Anat Rec 1958; 132: 247-59.

8 Loran MR, Allthausen TL. Cellular proliferation of intestinal epithelia in the rat two months after partial resection of the ileum. F Biophys Biochem Cytol 1960; 7: 667-71.

9 Weser E, Hernandez MH. Studies of small bowel adaptation after intestinal resection in the rat. Gastroenterology $1971 ; 60$ 69-75.

10 McCarthy DM, Kim YS. Changes in sucrase, enterokinase and peptide hydrolase after intestinal resection. The association of cellular hyperplasia and adaptation. $\mathcal{f}$ Clin Inves 1973; 52: 942-51.

11 Menge $\mathrm{H}$, Robinson JWL. The relationship between the structural and functional alterations in the rat small intestine following proximal resection of varying extents. Res Exp Med 1978; 173: 41-53.

12 Wilson HD, Miller T, Ogesen B, Schedl HP, Failla ML Loven DP. Adaptation of the duodenum and ileum of the rat to mid-gut resection: enzyme activity and trace metal status. to mid-gut resection: enzyme activity

13 Bury KD. Disaccharidase activity and carbohydrate absorp tion after intestinal resection. Surg Forum 1971; 22: 367-9.

14 Gutschmidt S, Kaul W, Menge H, Riecken EO. The adaptive response of disaccaridase activities at different sites along the villus epithelium after proximal intestinal resection in the rat. A microdensitometric study of enzyme kinetics. Res $E x$ Med 1983; 182: 203-13.

15 Chaves M, Smith MW, Williamson RCN. Increased activity of digestive enzymes in ileal enterocytes adapting to proximal small bowel resection. Gut 1987; 28: 981-7.

16 Keelan M, Walker K, Thomson ABR. Resection of rabbit ileum: effect on brush border membrane enzyme markers and lipids. Can F Physiol Pharmacol 1985; 63: 1528-32.

17 Young GP, Morton CL, Rose IS, Taranto TM, Bhathal PS. Effects of intestinal adaptation on insulin binding to villus Effects of intestinal adaptation on insulin binding
cell membranes. Gut 1987; 28 (suppl 1): 57-62.

18 Nygaard K. Resection of the small intestine in rats. III. Morphological changes in the intestinal tract. Acta Chir Mcand 1967; 133: 233-48.

19 Weiser MM. Intestinal epithelial cell surface membrane glycoprotein synthesis. I. An indicator of cellular differentiation. $\mathcal{f}$ Biol Chem 1973; 248: 2536-41. 
20 Gratecos $M$, Knibiehler $M$, Benoit V, Sémériva $M$. Plasma membranes from rat intestinal epithelial cells at different stages of maturation. I. Preparation and characterization of plasma membrane subfractions originating from crypt cells and from villous cells. Biochim Biophys Acta 1978; 512: 50824.

21 Dahlquist A. Assay of intestinal disaccharidases. Anal Biochem 1968; 22: 99-107.

22 Young GP, Das L. Influence of duodenal secretions and its components on release and activities of human brush-border enzymes. Biochim Biophys Acta 1990; 1022: 393-400.

23 Kapuscinski J, Skoczylas B. Simple and rapid fluormetric method for DNA microassay. Anal Biochem 1977; 88: 252-7.

24 Cheng H, McCulloch C, Bjerknes M. Effects of $30 \%$ intestina resection on whole population cell kinetics of mouse in testinal epithelium. Anat $\operatorname{Rec} 1986 ; 215$ : 35-41.

25 Gleeson MH, Dowling RH, Peters TJ. Biochemical changes in intestinal mucosa after experimental small bowel by-pass in the rat. Clin Sci 1972; 43: 743-57.

26 Skagen DW. Mucosal growth and enzyme activity during the early phase of adaptation after jejunal bypass in the rat. Scand 7 Gastroenterol 1984; 19: 983-9.

27 Dowling RH. Intestinal adaptation and its mechanisms. Top Gastroenterol 1982; 10: 135-56.

28 Gray JP, Trevino H, Nichols S, Michel A, Urban E, Hoyumpa A. Effects of intestinal resection on microviscosity of rat enterocyte brush border membrane. Gastroenterology 1984 86: 1096 